\title{
On convergence theorems for total asymptotically nonexpansive nonself-mappings in Banach spaces
}

\author{
Esra Yolacan ${ }^{a}$, Hukmi Kiziltunc ${ }^{\mathrm{a}, *}$ \\ ${ }^{a}$ Department of Mathematics, Faculty of Science, Ataturk University, Erzurum, Turkey. \\ Dedicated to George A Anastassiou on the occasion of his sixtieth birthday \\ Communicated by Professor V. Berinde
}

\begin{abstract}
In this paper, we define and study new strong convergence theorems of the modified Mann and the modified Ishikawa iterative scheme with errors for nonself-mappings which are total asymptotically nonexpansive in a uniformly convex Banach space.
\end{abstract}

Keywords: Asymptotically nonexpansive nonself-mappings, total asymptotically nonexpansive nonself-mappings, common fixed point, uniformly convex Banach space.

2010 MSC: Primary 47H09; Secondary 47H10; Tertiary 46B20.

\section{Introduction}

Let $E$ be a real Banach space and $K$ be a nonempty subset of $E$. A mapping $T: K \rightarrow K$ is called nonexpansive if $\|T x-T y\| \leq\|x-y\|$ for all $x, y \in K$. A mapping $T: K \rightarrow K$ is called asymptotically nonexpansive if there exists a sequence $\left\{k_{n}\right\} \subset[1, \infty)$ with $k_{n} \rightarrow 1$ such that

$$
\left\|T^{n} x-T^{n} y\right\| \leq k_{n}\|x-y\|
$$

for all $x, y \in K$ and $n \geq 1$. Goebel and Kirk [8] proved that if $K$ is a nonempty closed and bounded subset of a uniformly convex Banach space, then every asymptotically nonexpansive self-mapping has a fixed point.

A mapping $T$ is said to be asymptotically nonexpansive in the intermediate sense (see, e.g., 3]) if it is continuous and the following inequality holds:

$$
\limsup _{n \rightarrow \infty} \sup _{x, y \in K}\left(\left\|T^{n} x-T^{n} y\right\|-\|x-y\|\right) \leq 0 .
$$

\footnotetext{
* Corresponding author

Email addresses: yolacanesra@gmail.com (Esra Yolacan), hukmu@atauni.edu.tr (Hukmi Kiziltunc)
} 
If $F(T):=\{x \in K: T x=x\} \neq \varnothing$ and 1.2 holds for all $x \in K, y \in F(T)$, then $T$ is called asymptotically quasi - nonexpansive in the intermediate sense. Observe that if we define

$$
a_{n}:=\sup _{x, y \in K}\left(\left\|T^{n} x-T^{n} y\right\|-\|x-y\|\right), \text { and } \sigma_{n}=\max \left\{0, a_{n}\right\},
$$

then $\sigma_{n} \rightarrow 0$ as $n \rightarrow \infty$ and 1.2 reduces to

$$
\left\|T^{n} x-T^{n} y\right\| \leq\|x-y\|+\sigma_{n}, \quad \text { for all } x, y \in K, n \geq 1 .
$$

The class of mappings which are asymptotically nonexpansive in the intermediate sense was introduced by Bruck et al. [3]. It is known [13] that if $K$ is a nonempty closed convex bounded subset of a uniformly convex Banach space $E$ and $T$ is a self-mapping of $K$ which is asymptotically nonexpansive in the intermediate sense, then $T$ has a fixed point. It is worth mentioning that the class of mappings which are asymptotically nonexpansive in the intermediate sense contains properly the class of asymptotically nonexpansive mappings.

Albert et al. [1] introduced a more general class of asymptotically nonexpansive mappings called total asymptotically nonexpansive mappings and studied methods of approximation of fixed points of mappings belonging to this class.

Definition 1.1. A mapping $T: K \rightarrow K$ is said to be total asymptotically nonexpansive if there exist nonnegative real sequences $\left\{\mu_{n}\right\}$ and $\left\{l_{n}\right\}, n \geq 1$ with $\mu_{n}, l_{n} \rightarrow 0$ as $n \rightarrow \infty$ and strictly increasing continuous function $\phi: \mathbb{R}^{+} \rightarrow \mathbb{R}^{+}$with $\phi(0)=0$ such that for all $x, y \in K$,

$$
\left\|T^{n} x-T^{n} y\right\| \leq\|x-y\|+\mu_{n} \phi(\|x-y\|)+l_{n}, \quad n \geq 1 .
$$

Remark 1.2. If $\phi(\lambda)=\lambda$, then 1.5 reduces to

$$
\left\|T^{n} x-T^{n} y\right\| \leq\left(1+\mu_{n}\right)\|x-y\|+l_{n}, \quad n \geq 1 .
$$

In addition, if $l_{n}=0$ for all $n \geq 1$, then total asymptotically nonexpansive mappings coincide with asymptotically nonexpansive mappings. If $\mu_{n}=0$ and $l_{n}=0$ for all $n \geq 1$, we obtain from (1.5) the class of mappings that includes the class of nonexpansive mappings. If $\mu_{n}=0$ and $l_{n}=\sigma_{n}=\max \left\{0, a_{n}\right\}$, where $a_{n}:=\sup _{x, y \in K}\left(\left\|T^{n} x-T^{n} y\right\|-\|x-y\|\right)$ for all $n \geq 1$, then 1.5 reduces to 1.4 which has been studied as mappings asymptotically nonexpansive in the intermediate sense.

Iterative techniques for nonexpansive and asymptotically nonexpansive mappings in Banach space including Mann type and Ishikawa type iteration processes have been studied extensively by various authors; see [2], [4], [5], 8], [10], [11], [16], [17], [19] and [21]. However, if the domain of $T, D(T)$, is a proper subset of $E$ (and this is the case in several applications), and $T$ maps $D(T)$ into $E$, then the iteration processes of Mann type and Ishikawa type studied by the authors mentioned above, and their modifications introduced may fail to be well defined.

A subset $K$ of $E$ is said to be a retract of $E$ if there exists a continuous map $P: E \rightarrow E$ such that $P x=x$, for all $x \in K$. Every closed convex subset of a uniformly convex Banach space is a retract. A map $P: E \rightarrow K$ is said to be a retraction if $P^{2}=P$. It follows that if a map $P$ is a retraction, then $P y=y$ for all $y \in R(P)$, the range of $P$.

The concept of asymptotically nonexpansive nonself-mappings was firstly introduced by Chidume et al. [5] as the generalization of asymptotically nonexpansive self-mappings. The asymptotically nonexpansive nonself-mapping is defined as follows:

Let $K$ be a nonempty subset of real normed linear space $E$. Let $P: E \rightarrow K$ be the nonexpansive retraction of $E$ onto $K$. A nonself mapping $T: K \rightarrow E$ is called asymptotically nonexpansive if there exists sequence $\left\{k_{n}\right\} \subset[1, \infty), k_{n} \rightarrow 1(n \rightarrow \infty)$ such that

$$
\left\|T(P T)^{n-1} x-T(P T)^{n-1} y\right\| \leq k_{n}\|x-y\| \text { for all } x, y \in K, \quad n \geq 1 .
$$

Chidume et al. [6] introduce a more general class of total asymptotically nonexpansive mappings as the generalization of asymptotically nonexpansive nonself-mappings. 
Definition 1.3. Let $K$ be a nonempty closed and convex subset of $E$. Let $P: E \rightarrow K$ be the nonexpansive retraction of $E$ onto $K$. A nonself map $T: K \rightarrow E$ is said to be total asymptotically nonexpansive if there exist sequences $\left\{\mu_{n}\right\}_{n \geq 1},\left\{l_{n}\right\}_{n \geq 1}$ in $[0,+\infty)$ with $\mu_{n}, l_{n} \rightarrow 0$ as $n \rightarrow \infty$ and a strictly increasing continuous function $\phi:[0,+\infty) \rightarrow[0,+\infty)$ with $\phi(0)=0$ such that for all $x, y \in K$,

$$
\left\|T(P T)^{n-1} x-T(P T)^{n-1} y\right\| \leq\|x-y\|+\mu_{n} \phi(\|x-y\|)+l_{n}, \quad n \geq 1 .
$$

Proposition 1.4. [9] Let $K$ be a nonempty subset of $E$ which is also a nonexpansive retract of $E, T_{1}$, $T_{2}: K \rightarrow E$ be two total nonself asymptotically nonexpansive mappings. Then there exist nonnegative real sequences $\left\{\mu_{n}\right\}$ and $\left\{l_{n}\right\}, n \geq 1$ with $\mu_{n}, l_{n} \rightarrow 0$ as $n \rightarrow \infty$ and strictly increasing continuous function $\phi: \mathbb{R}^{+} \rightarrow \mathbb{R}^{+}$with $\phi(0)=0$ such that for all $x, y \in K$,

$$
\left\|T_{i}\left(P T_{i}\right)^{n-1} x-T_{i}\left(P T_{i}\right)^{n-1} y\right\| \leq\|x-y\|+\mu_{n} \phi(\|x-y\|)+l_{n}, \quad n \geq 1,
$$

for $i=1,2$.

Proof. Since $T_{i}: K \rightarrow E$ is a total nonself asymptotically nonexpansive mappings for $i=1,2$, there exist nonnegative real sequences $\left\{\mu_{i n}\right\},\left\{l_{i n}\right\}, n \geq 1$ with $\mu_{i n}, l_{i n} \rightarrow 0$ as $n \rightarrow \infty$ and strictly increasing continuous function $\phi_{i}: \mathbb{R}^{+} \rightarrow \mathbb{R}^{+}$with $\phi_{i}(0)=0$ such that for all $x, y \in K$,

$$
\left\|T_{i}\left(P T_{i}\right)^{n-1} x-T_{i}\left(P T_{i}\right)^{n-1} y\right\| \leq\|x-y\|+\mu_{i n} \phi_{i}(\|x-y\|)+l_{\text {in }}, \quad n \geq 1 .
$$

Setting

$$
\begin{aligned}
\mu_{n} & =\max \left\{\mu_{1 n}, \mu_{2 n}\right\}, \quad l_{n}=\max \left\{l_{1 n}, l_{2 n}\right\}, \\
\phi(a) & =\max \left\{\phi_{1}(a), \phi_{2}(a)\right\}, \quad \text { for } a \geq 0,
\end{aligned}
$$

then we get that there exist nonnegative real sequences $\left\{\mu_{n}\right\}$ and $\left\{l_{n}\right\}, n \geq 1$ with $\mu_{n}, l_{n} \rightarrow 0$ as $n \rightarrow \infty$ and strictly increasing continuous function $\phi: \mathbb{R}^{+} \rightarrow \mathbb{R}^{+}$with $\phi(0)=0$ such that

$$
\begin{aligned}
\left\|T_{i}\left(P T_{i}\right)^{n-1} x-T_{i}\left(P T_{i}\right)^{n-1} y\right\| & \leq\|x-y\|+\mu_{i n} \phi_{i}(\|x-y\|)+l_{i n} \\
& \leq\|x-y\|+\mu_{n} \phi(\|x-y\|)+l_{n}, \quad n \geq 1,
\end{aligned}
$$

for all $x, y \in K$, and each $i=1,2$.

In [18], Schu introduced the modified Mann and the modified Ishikawa iterative schemes. Recently, Kim and Kim [12] considered the modified Mann and the modified Ishikawa iterative schemes with errors in the sense of $\mathrm{Xu}[22$ of a mapping which is asymptotically nonexpansive in the intermediate sense in a uniformly convex Banach space. In 2009, Nilsrakoo et al. [15] introduced a new strong convergence theorem for non-Lipschitzian mappings in a uniformly convex Banach space. The scheme is defined as follows.

Let $E$ be a real uniformly convex Banach space and $K$ be a nonempty subset of $E$ which is also a nonexpansive retract of $E$. Let $T_{1}, T_{2}: K \rightarrow E$ be given two total nonself asymptotically nonexpansive mappings with sequences $\left\{\mu_{n}\right\}_{n \geq 1},\left\{l_{n}\right\}_{n \geq 1} \subset[0,+\infty)$ such that $\sum_{n=1}^{\infty} \mu_{n}<\infty, \sum_{n=1}^{\infty} l_{n}<\infty$. Then for a given $x_{1} \in K$, compute the sequences $\left\{x_{n}\right\}$ and $\left\{y_{n}\right\}$ by the iterative schemes

$$
\begin{aligned}
y_{n} & =P\left(\alpha_{n}^{\prime} x_{n}+\beta_{n}^{\prime} T_{1}\left(P T_{1}\right)^{n-1} x_{n}+\gamma_{n}^{\prime} v_{n}\right), \\
x_{n+1} & =P\left(\alpha_{n} y_{n}+\beta_{n} T_{2}\left(P T_{2}\right)^{n-1} y_{n}+\gamma_{n} u_{n}\right), \quad n \geq 1,
\end{aligned}
$$

where $\left\{\alpha_{n}\right\},\left\{\beta_{n}\right\},\left\{\gamma_{n}\right\},\left\{\alpha_{n}^{\prime}\right\},\left\{\beta_{n}^{\prime}\right\}$ and $\left\{\gamma_{n}^{\prime}\right\}$ are appropriate sequences in $[0,1]$ with $\alpha_{n}+\beta_{n}+\gamma_{n}=$ $\alpha_{n}^{\prime}+\beta_{n}^{\prime}+\gamma_{n}^{\prime}=1$, and $\left\{u_{n}\right\}$ and $\left\{v_{n}\right\}$ are bounded sequences in $K$. The iterative scheme 1.10 is called the modified Ishikawa iterative scheme with errors in the sense of $\mathrm{Xu}$. 
If $\beta_{n}^{\prime}=\gamma_{n}^{\prime} \equiv 0$ and $\alpha_{n}^{\prime} \equiv 1$, then 1.10 reduces to the modified Mann iterative scheme with errors in the sense of $\mathrm{Xu}$

$$
x_{n+1}=P\left(\alpha_{n} x_{n}+\beta_{n} T_{2}\left(P T_{2}\right)^{n-1} x_{n}+\gamma_{n} u_{n}\right), \quad n \geq 1,
$$

where $\left\{\alpha_{n}\right\},\left\{\beta_{n}\right\}$ and $\left\{\gamma_{n}\right\}$ are appropriate sequences in $[0,1]$ with $\alpha_{n}+\beta_{n}+\gamma_{n}=1$, and $\left\{u_{n}\right\}$ is a bounded sequence in $K$.

If $T_{1}=T_{2}=T$ are self-mappings and $\beta_{n}^{\prime}=\gamma_{n}^{\prime} \equiv 0$ and $\alpha_{n}^{\prime} \equiv 1$, then 1.10 reduces to the iteration defined by Nilsrakoo [15]

$$
x_{n+1}=\alpha_{n} x_{n}+\beta_{n} T^{n} x_{n}+\gamma_{n} u_{n}, \quad n \geq 1,
$$

where $\left\{\alpha_{n}\right\},\left\{\beta_{n}\right\}$ and $\left\{\gamma_{n}\right\}$ are appropriate sequences in $[0,1]$ with $\alpha_{n}+\beta_{n}+\gamma_{n}=1$, and $\left\{u_{n}\right\}$ is a bounded sequence in $K$.

If $T_{1}=T_{2}=T$ are self-mappings and $\beta_{n}^{\prime}=\gamma_{n}=\gamma_{n}^{\prime} \equiv 0$ and $\alpha_{n}^{\prime} \equiv 1$, then 1.10 reduces to modified Mann iterative scheme.

The purpose of this paper is to define and study strong convergence theorems of the modified Ishikawa iterative scheme with errors for two total asymptotically nonexpansive nonself-mappings in uniformly convex Banach space.

\section{Preliminaries}

Now, we recall the well-known concepts and results.

Let $E$ be a Banach space with dimension $E \geq 2$. The modulus of $E$ is the function $\delta_{E}:(0,2] \rightarrow[0,1]$ defined by

$$
\delta_{E}(\varepsilon)=\inf \left\{1-\left\|\frac{1}{2}(x+y)\right\|:\|x\|=\|y\|=1, \varepsilon=\|x-y\|\right\} .
$$

A Banach space $E$ is uniformly convex if and only if $\delta_{E}(\varepsilon)>0$ for all $\varepsilon \in(0,2]$.

The mapping $T: K \rightarrow E$ with $F(T) \neq \emptyset$ is said to satisfy condition $(A)$ [20] if there is a nondecreasing function $f:[0, \infty) \rightarrow[0, \infty)$ with $f(0)=0, f(t)>0$ for all $t \in(0, \infty)$ such that

$$
\|x-T x\| \geq f(d(x, F(T)))
$$

for all $x \in K$, where $d(x, F(T))=\inf \{\|x-p\|: p \in F(T)\}$.

Two mappings $T_{1}, T_{2}: K \rightarrow E$ are said to satisfy condition $\left(A^{\prime}\right)$ [14] if there is a nondecreasing function $f:[0, \infty) \rightarrow[0, \infty)$ with $f(0)=0, f(t)>0$ for all $t \in(0, \infty)$ such that

$$
\frac{1}{2}\left(\left\|x-T_{1} x\right\|+\left\|x-T_{2} x\right\|\right) \geq f(d(x, \mathcal{F}))
$$

for all $x \in K$ where $d(x, \mathcal{F})=\inf \left\{\|x-p\|: p \in \mathcal{F}=F\left(T_{1}\right) \cap F\left(T_{2}\right)\right\}$.

Note that condition $\left(A^{\prime}\right)$ reduces to condition $(A)$ when $T_{1}=T_{2}$ and hence is more general than the demicompactness of $T_{1}$ and $T_{2}$ [20. A mapping $T: K \rightarrow K$ is called: (1) demicompact if any bounded sequence $\left\{x_{n}\right\}$ in $K$ such that $\left\{x_{n}-T x_{n}\right\}$ converges has a convergent subsequence; (2) semicompact (or hemicompact) if any bounded sequence $\left\{x_{n}\right\}$ in $K$ such that $\left\{x_{n}-T x_{n}\right\} \rightarrow 0$ as $n \rightarrow \infty$ has a convergent subsequence. Every demicompact mapping is semicompact but the converse is not true in general.

Senter and Dotson [20] have approximated fixed points of a nonexpansive mapping $T$ by Mann iterates, whereas Maiti and Ghosh [14] and Tan and Xu [21] have approximated the fixed points using Ishikawa iterates under the condition $(A)$ of Senter and Dotson [20]. Tan and Xu [21] pointed out that condition $(A)$ is weaker than the compactness of $K$. We shall use condition $\left(A^{\prime}\right)$ instead of compactness of $K$ to study the strong convergence of $\left\{x_{n}\right\}$ defined in 1.10 .

In the sequel, we need the following useful known lemmas to prove our main results. 
Lemma 2.1. [21] Let $\left\{a_{n}\right\},\left\{b_{n}\right\}$ and $\left\{c_{n}\right\}$ be sequences of nonnegative real numbers satisfying the inequality

$$
a_{n+1} \leq\left(1+b_{n}\right) a_{n}+c_{n}, \quad n \geq 1 .
$$

If $\sum_{n=1}^{\infty} c_{n}<\infty$ and $\sum_{n=1}^{\infty} b_{n}<\infty$, then

(i) $\lim _{n \rightarrow \infty} a_{n}$ exists;

(ii) In particular, if $\left\{a_{n}\right\}$ has a subsequence which converges strongly to zero, then $\lim _{n \rightarrow \infty} a_{n}=0$.

Lemma 2.2. 77 Let $E$ be a uniformly convex Banach space and $B_{r}=\{x \in E:\|x\| \leq r\}$. Then there exists a continuous, strictly increasing, and convex function $g:[0, \infty) \rightarrow[0, \infty), g(0)=0$ such that

$$
\|\alpha x+\beta y+\gamma z\|^{2} \leq \alpha\|x\|^{2}+\beta\|y\|^{2}+\gamma\|z\|^{2}-\alpha \beta g(\|x-y\|),
$$

for all $x, y, z \in B_{r}$, and all $\alpha, \beta, \gamma \in[0,1]$ with $\alpha+\beta+\gamma=1$.

\section{Main Results}

We shall make use of the following lemmas.

Lemma 3.1. Let $E$ be a real Banach space, let $K$ be a nonempty closed convex subset of $E$ which is also a nonexpansive retract of $E$, and $T_{1}, T_{2}: K \rightarrow E$ be two total asymptotically nonexpansive nonselfmappings with sequences $\left\{\mu_{n}\right\},\left\{l_{n}\right\}$ defined by 1.9$)$ such that $\sum_{n=1}^{\infty} \mu_{n}<\infty, \sum_{n=1}^{\infty} l_{n}<\infty$ and $\mathcal{F}:=F\left(T_{1}\right) \cap$ $F\left(T_{2}\right)=\left\{x \in K: T_{1} x=T_{2} x=x\right\} \neq \varnothing$. Assume that there exist $M, M^{*}>0$ such that $\phi(\lambda) \leq M^{*} \lambda$ for all $\lambda \geq M$. Suppose that $\left\{u_{n}\right\},\left\{v_{n}\right\}$ are bounded sequences in $K$ such that $\sum_{n=1}^{\infty} \gamma_{n}<\infty, \sum_{n=1}^{\infty} \gamma_{n}^{\prime}<\infty$ and $\sum_{n=1}^{\infty} \mu_{n} \gamma_{n}^{\prime}<\infty$. Starting from an arbitrary $x_{1} \in K$, define the sequence $\left\{x_{n}\right\}$ by recursion (1.10). Then, the sequence $\left\{x_{n}\right\}$ is bounded and $\lim _{n \rightarrow \infty}\left\|x_{n}-p\right\|$ exists, $p \in \mathcal{F}$.

Proof. Let $p \in \mathcal{F}$. Since $\left\{u_{n}\right\}$ and $\left\{v_{n}\right\}$ are bounded sequences in $K$, we have

$$
r=\max \left\{\sup _{n \geq 1}\left\|u_{n}-p\right\|, \sup _{n \geq 1}\left\|v_{n}-p\right\|\right\} .
$$

By using (1.10), we have

$$
\begin{aligned}
\left\|y_{n}-p\right\| & =\left\|P\left(\alpha_{n}^{\prime} x_{n}+\beta_{n}^{\prime} T_{1}\left(P T_{1}\right)^{n-1} x_{n}+\gamma_{n}^{\prime} v_{n}\right)-p\right\| \\
& \leq \alpha_{n}^{\prime}\left\|x_{n}-p\right\|+\beta_{n}^{\prime}\left\|T_{1}\left(P T_{1}\right)^{n-1} x_{n}-p\right\|+\gamma_{n}^{\prime}\left\|v_{n}-p\right\| \\
& \leq \alpha_{n}^{\prime}\left\|x_{n}-p\right\|+\beta_{n}^{\prime}\left[\left\|x_{n}-p\right\|+\mu_{n} \phi\left(\left\|x_{n}-p\right\|\right)+l_{n}\right]+\gamma_{n}^{\prime} r \\
& \leq\left(\alpha_{n}^{\prime}+\beta_{n}^{\prime}\right)\left\|x_{n}-p\right\|+\beta_{n}^{\prime} \mu_{n} \phi\left(\left\|x_{n}-p\right\|\right)+\beta_{n}^{\prime} l_{n}+\gamma_{n}^{\prime} r .
\end{aligned}
$$

Note that $\phi$ is an increasing function, it follows that $\phi(\lambda) \leq \phi(M)$ whenever $\lambda \leq M$ and (by hypothesis) $\phi(\lambda) \leq M^{*} \lambda$ if $\lambda \geq M$. In either case, we have

$$
\phi(\lambda) \leq \phi(M)+M^{*} \lambda
$$

for some $M, M^{*}>0$. Thus, from (3.2) and (3.3), we have

$$
\begin{aligned}
\left\|y_{n}-p\right\| & \leq\left\|x_{n}-p\right\|+\beta_{n}^{\prime} \mu_{n}\left[\phi(M)+M^{*}\left\|x_{n}-p\right\|\right]+\beta_{n}^{\prime} l_{n}+\gamma_{n}^{\prime} r \\
& \leq\left(1+Q_{1} \mu_{n}\right)\left\|x_{n}-p\right\|+Q_{1}\left(\mu_{n}+l_{n}\right)+\gamma_{n}^{\prime} r
\end{aligned}
$$


for some constant $Q_{1}>0$. Similarly, we have

$$
\begin{aligned}
\left\|x_{n+1}-p\right\| & \leq \alpha_{n}\left\|y_{n}-p\right\|+\beta_{n}\left\|T_{2}\left(P T_{2}\right)^{n-1} y_{n}-p\right\|+\gamma_{n}\left\|u_{n}-p\right\| \\
& \leq \alpha_{n}\left\|y_{n}-p\right\|+\beta_{n}\left[\left\|y_{n}-p\right\|+\mu_{n} \phi\left(\left\|y_{n}-p\right\|\right)+l_{n}\right]+\gamma_{n} r \\
& \leq\left(\alpha_{n}+\beta_{n}\right)\left\|y_{n}-p\right\|+\beta_{n} \mu_{n} \phi\left(\left\|y_{n}-p\right\|\right)+\beta_{n} l_{n}+\gamma_{n} r \\
& \leq\left\|y_{n}-p\right\|+\beta_{n} \mu_{n}\left[\phi(M)+M^{*}\left\|y_{n}-p\right\|\right]+\beta_{n} l_{n}+\gamma_{n} r \\
& \leq\left(1+Q_{2} \mu_{n}\right)\left\|y_{n}-p\right\|+Q_{2}\left(\mu_{n}+l_{n}\right)+\gamma_{n} r
\end{aligned}
$$

for some constant $Q_{2}>0$. Using (3.4) and (3.5), we obtain

$$
\begin{aligned}
\left\|x_{n+1}-p\right\| \leq & \left(1+Q_{2} \mu_{n}\right)\left[\left(1+Q_{1} \mu_{n}\right)\left\|x_{n}-p\right\|+Q_{1}\left(\mu_{n}+l_{n}\right)+\gamma_{n}^{\prime} r\right] \\
& +Q_{2}\left(\mu_{n}+l_{n}\right)+\gamma_{n} r \\
\leq & \left\|x_{n}-p\right\|+\left(Q_{1}+Q_{2}+Q_{2} \mu_{n} Q_{1}\right) \mu_{n}\left\|x_{n}-p\right\| \\
& +Q_{1}\left(\mu_{n}+l_{n}\right)+Q_{1} Q_{2} \mu_{n}\left(\mu_{n}+l_{n}\right)+\gamma_{n}^{\prime} r+Q_{2} \mu_{n} \gamma_{n}^{\prime} r \\
& +Q_{2}\left(\mu_{n}+l_{n}\right)+\gamma_{n} r \\
\leq & \left(1+Q_{3} \mu_{n}\right)\left\|x_{n}-p\right\|+Q_{3}\left(\mu_{n}+l_{n}\right)+\gamma_{n}^{\prime} r+Q_{2} \mu_{n} \gamma_{n}^{\prime} r+\gamma_{n} r \\
\leq & \left(1+Q_{3} \mu_{n}\right)\left\|x_{n}-p\right\|+Q_{3}\left(\mu_{n}+l_{n}\right)+\Gamma_{(1)}^{n},
\end{aligned}
$$

where $\Gamma_{(1)}^{n}=\gamma_{n}^{\prime} r+Q_{2} \mu_{n} \gamma_{n}^{\prime} r+\gamma_{n} r$ and for some constant $Q_{3}>0$. Since $\sum_{n=1}^{\infty} \gamma_{n}<\infty, \sum_{n=1}^{\infty} \gamma_{n}^{\prime}<\infty$ and $\sum_{n=1}^{\infty} \mu_{n} \gamma_{n}^{\prime}<\infty$, we have $\sum_{n=1}^{\infty} \Gamma_{(1)}^{n}<\infty$. Also, since $\sum_{n=1}^{\infty} \mu_{n}<\infty, \sum_{n=1}^{\infty} l_{n}<\infty$ and $\sum_{n=1}^{\infty} \Gamma_{(1)}^{n}<\infty$, by Lemma 2.1, we get $\lim _{n \rightarrow \infty}\left\|x_{n}-p\right\|$ exists. This completes the proof.

Lemma 3.2. Let $E$ be a uniformly convex Banach space, let $K$ be a nonempty closed convex subset of $E$ which is also a nonexpansive retract of $E$, and $T_{1}, T_{2}: K \rightarrow E$ be two total asymptotically nonexpansive nonself-mappings with sequences $\left\{\mu_{n}\right\},\left\{l_{n}\right\}$ defined by 1.9 such that $\sum_{n=1}^{\infty} \mu_{n}<\infty, \sum_{n=1}^{\infty} l_{n}<\infty$ and $\mathcal{F}:=$ $F\left(T_{1}\right) \cap F\left(T_{2}\right)=\left\{x \in K: T_{1} x=T_{2} x=x\right\} \neq \varnothing$. Assume that there exist $M, M^{*}>0$ such that $\phi(\lambda) \leq M^{*} \lambda$ for all $\lambda \geq M$. Suppose that $\left\{u_{n}\right\},\left\{v_{n}\right\}$ are bounded sequences in $K$ such that $\sum_{n=1}^{\infty} \gamma_{n}<\infty, \sum_{n=1}^{\infty} \gamma_{n}^{\prime}<\infty$ . Starting from an arbitrary $x_{1} \in K$, define the sequence $\left\{x_{n}\right\}$ by recursion (1.10). Suppose that

(i) $0<\liminf _{n \rightarrow \infty} \alpha_{n}$ and $0<\liminf _{n \rightarrow \infty} \gamma_{n}<\limsup _{n \rightarrow \infty} \gamma_{n}<1$,

(ii) $0<\liminf _{n \rightarrow \infty} \alpha_{n}^{\prime}$ and $0<\liminf _{n \rightarrow \infty} \gamma_{n}^{\prime}<\limsup _{n \rightarrow \infty} \gamma_{n}^{\prime}<1$.

Then $\lim _{n \rightarrow \infty}\left\|T_{i}\left(P T_{i}\right)^{n-1} x_{n}-x_{n}\right\|=0$ for $i=1,2$.

Proof. Let $p \in \mathcal{F}$. It follows from Lemma 3.1 that $\left\{x_{n}-p\right\},\left\{T_{1}\left(P T_{1}\right)^{n-1} x_{n}-p\right\},\left\{y_{n}-p\right\},\left\{T_{2}\left(P T_{2}\right)^{n-1} y_{n}-p\right\}$, $\left\{u_{n}-p\right\}$ and $\left\{v_{n}-p\right\}$ are all bounded. We may assume that such sequences belong to $B_{r}$ where $r>0$. 
Using Lemma 2.2, we have, for some constant $R_{1}>0$, that

$$
\begin{aligned}
\left\|y_{n}-p\right\|^{2} \leq & \alpha_{n}^{\prime}\left\|x_{n}-p\right\|^{2}+\beta_{n}^{\prime}\left\|T_{1}\left(P T_{1}\right)^{n-1} x_{n}-p\right\|^{2}+\gamma_{n}^{\prime}\left\|v_{n}-p\right\|^{2} \\
& -\alpha_{n}^{\prime} \beta_{n}^{\prime} g\left(\left\|T_{1}\left(P T_{1}\right)^{n-1} x_{n}-x_{n}\right\|\right) \\
\leq & \alpha_{n}^{\prime}\left\|x_{n}-p\right\|^{2}+\beta_{n}^{\prime}\left[\left\|x_{n}-p\right\|+\mu_{n} \phi\left(\left\|x_{n}-p\right\|\right)+l_{n}\right]^{2} \\
& +\gamma_{n}^{\prime} r^{2}-\alpha_{n}^{\prime} \beta_{n}^{\prime} g\left(\left\|T_{1}\left(P T_{1}\right)^{n-1} x_{n}-x_{n}\right\|\right) \\
\leq & \left(\alpha_{n}^{\prime}+\beta_{n}^{\prime}\right)\left\|x_{n}-p\right\|^{2}+R_{1}\left(\mu_{n}+l_{n}\right) \\
& +\gamma_{n}^{\prime} r^{2}-\alpha_{n}^{\prime} \beta_{n}^{\prime} g\left(\left\|T_{1}\left(P T_{1}\right)^{n-1} x_{n}-x_{n}\right\|\right) \\
\leq & \left\|x_{n}-p\right\|^{2}+R_{1}\left(\mu_{n}+l_{n}\right) \\
& +\gamma_{n}^{\prime} r^{2}-\alpha_{n}^{\prime} \beta_{n}^{\prime} g\left(\left\|T_{1}\left(P T_{1}\right)^{n-1} x_{n}-x_{n}\right\|\right) .
\end{aligned}
$$

It follows from Lemma 2.2 that

$$
\begin{aligned}
\left\|x_{n+1}-p\right\|^{2} \leq & \alpha_{n}\left\|y_{n}-p\right\|^{2}+\beta_{n}\left\|T_{2}\left(P T_{2}\right)^{n-1} y_{n}-p\right\|^{2}+\gamma_{n}\left\|u_{n}-p\right\|^{2} \\
& -\alpha_{n} \beta_{n} g\left(\left\|T_{2}\left(P T_{2}\right)^{n-1} y_{n}-x_{n}\right\|\right) \\
\leq & \alpha_{n}\left\|y_{n}-p\right\|^{2}+\beta_{n}\left[\left\|y_{n}-p\right\|+\mu_{n} \phi\left(\left\|y_{n}-p\right\|\right)+l_{n}\right]^{2} \\
& +\gamma_{n} r^{2}-\alpha_{n} \beta_{n} g\left(\left\|T_{2}\left(P T_{2}\right)^{n-1} y_{n}-x_{n}\right\|\right) \\
\leq & \left(\alpha_{n}+\beta_{n}\right)\left\|y_{n}-p\right\|^{2}+R_{2}\left(\mu_{n}+l_{n}\right)+\gamma_{n} r^{2} \\
\leq & \left\|y_{n}-p\right\|^{2}+R_{2}\left(\mu_{n}+l_{n}\right)+\gamma_{n} r^{2}
\end{aligned}
$$

for some constant $R_{2}>0$. Using (3.7) and (3.8), we have, for some constant $R_{3}>0$, that

$$
\begin{aligned}
& \left\|x_{n+1}-p\right\|^{2} \\
\leq & {\left[\left\|x_{n}-p\right\|^{2}+R_{1}\left(\mu_{n}+l_{n}\right)+\gamma_{n}^{\prime} r^{2}-\alpha_{n}^{\prime} \beta_{n}^{\prime} g\left(\left\|T_{1}\left(P T_{1}\right)^{n-1} x_{n}-x_{n}\right\|\right)\right] } \\
& +R_{2}\left(\mu_{n}+l_{n}\right)+\gamma_{n} r^{2} \\
\leq & \left\|x_{n}-p\right\|^{2}+R_{3}\left(\mu_{n}+l_{n}\right)+\xi_{(1)}^{n}-\alpha_{n}^{\prime}\left(1-\alpha_{n}^{\prime}-\gamma_{n}^{\prime}\right) g\left(\left\|T_{1}\left(P T_{1}\right)^{n-1} x_{n}-x_{n}\right\|\right)
\end{aligned}
$$

where $\xi_{(1)}^{n}=\gamma_{n}^{\prime} r^{2}+\gamma_{n} r^{2}$. Since $\sum_{n=1}^{\infty} \gamma_{n}<\infty, \sum_{n=1}^{\infty} \gamma_{n}^{\prime}<\infty$, we have $\sum_{n=1}^{\infty} \xi_{(1)}^{n}<\infty$. Also, since $0<\liminf _{n \rightarrow \infty} \alpha_{n}^{\prime}$ and $0<\liminf _{n \rightarrow \infty} \gamma_{n}^{\prime}<\lim _{\sup _{n \rightarrow \infty}} \gamma_{n}^{\prime}<1$, there exists $n_{0} \in \mathbb{N}$ and $m_{1}, m_{2}, m_{3} \in(0,1)$ such that $0<m_{1}<\alpha_{n}^{\prime}<m_{2}<1$ and $0<\gamma_{n}^{\prime}<m_{3}<1$ for all $n \geq n_{0}$. It follows from (3.9) that

$$
\begin{aligned}
m_{1}\left(1-m_{2}-m_{3}\right) g\left(\left\|T_{1}\left(P T_{1}\right)^{n-1} x_{n}-x_{n}\right\|\right) \leq & \left(\left\|x_{n}-p\right\|^{2}-\left\|x_{n+1}-p\right\|^{2}\right) \\
& +R_{3}\left(\mu_{n}+l_{n}\right)+\xi_{(1)}^{n},
\end{aligned}
$$

for all $n>n_{0}$. Applying for $k \geq n_{0}$, we have

$$
\begin{aligned}
\sum_{n=n_{0}}^{k} g\left(\left\|T_{1}\left(P T_{1}\right)^{n-1} x_{n}-x_{n}\right\|\right) \leq & \frac{1}{m_{1}\left(1-m_{2}-m_{3}\right)}\left(\sum_{n=n_{0}}^{k}\left(\left\|x_{n}-p\right\|^{2}-\left\|x_{n+1}-p\right\|^{2}\right)\right. \\
& \left.+R_{3} \sum_{n=n_{0}}^{k}\left(\mu_{n}+l_{n}\right)+\sum_{n=n_{0}}^{k} \xi_{(1)}^{n}\right) \\
\leq & \frac{1}{m_{1}\left(1-m_{2}-m_{3}\right)}\left(\left\|x_{n_{0}}-p\right\|^{2}+R_{3} \sum_{n=n_{0}}^{k}\left(\mu_{n}+l_{n}\right)+\sum_{n=n_{0}}^{k} \xi_{(1)}^{n}\right) .
\end{aligned}
$$


Since $\sum_{n=1}^{\infty} \xi_{(1)}^{n}<\infty$, by letting $k \rightarrow \infty$ we get $\sum_{n=1}^{\infty} g\left(\left\|T_{1}\left(P T_{1}\right)^{n-1} x_{n}-x_{n}\right\|\right)<\infty$, therefore $\lim _{n \rightarrow \infty} g\left(\| T_{1}\left(P T_{1}\right)\right.$ 0 . Since $g$ strictly increasing and continuous at 0 with $g(0)=0$, it follows that

$$
\lim _{n \rightarrow \infty}\left\|T_{1}\left(P T_{1}\right)^{n-1} x_{n}-x_{n}\right\|=0 .
$$

Similarly, we may show that $\lim _{n \rightarrow \infty}\left\|T_{2}\left(P T_{2}\right)^{n-1} x_{n}-x_{n}\right\|=0$. The proof is completed.

Theorem 3.3. Let $E$ be a real Banach space, let $K$ be a nonempty closed convex subset of $E$ which is also a nonexpansive retract of $E$, and $T_{1}, T_{2}: K \rightarrow E$ be two continuous total asymptotically nonexpansive nonself-mappings with sequences $\left\{\mu_{n}\right\},\left\{l_{n}\right\}$ defined by 1.9 such that $\sum_{n=1}^{\infty} \mu_{n}<\infty, \sum_{n=1}^{\infty} l_{n}<\infty$ and $\mathcal{F}:=$ $F\left(T_{1}\right) \cap F\left(T_{2}\right)=\left\{x \in K: T_{1} x=T_{2} x=x\right\} \neq \varnothing$. Assume that there exist $M, M^{*}>0$ such that $\phi(\lambda) \leq M^{*} \lambda$ for all $\lambda \geq M$. Suppose that $\left\{u_{n}\right\},\left\{v_{n}\right\}$ are bounded sequences in $K$ such that $\sum_{n=1}^{\infty} \gamma_{n}<\infty, \sum_{n=1}^{\infty} \gamma_{n}^{\prime}<\infty$. Starting from an arbitrary $x_{1} \in K$, define the sequence $\left\{x_{n}\right\}$ by recursion (1.10). Then, the sequence $\left\{x_{n}\right\}$ converges strongly to a common fixed point of $\left\{T_{i}\right\}_{i=1}^{2}$ if and only if $\lim _{\inf _{n \rightarrow \infty}} d\left(x_{n}, \mathcal{F}\right)=0$, where $d\left(x_{n}, \mathcal{F}\right)=\inf _{p \in \mathcal{F}}\left\|x_{n}-p\right\|, n \geq 1$.

Proof. The necessity is obvious. Indeed, if $x_{n} \rightarrow q \in \mathcal{F}(n \rightarrow \infty)$, then

$$
d\left(x_{n}, \mathcal{F}\right)=\inf _{q \in \mathcal{F}} d\left(x_{n}, q\right) \leq\left\|x_{n}-q\right\| \rightarrow 0(n \rightarrow \infty) .
$$

Next, we prove sufficiency. It follows from (3.6) that for $p \in \mathcal{F}$, we have

$$
\begin{aligned}
\left\|x_{n+1}-p\right\| & \leq\left(1+Q_{3} \mu_{n}\right)\left\|x_{n}-p\right\|+Q_{3}\left(\mu_{n}+l_{n}\right)+\Gamma_{(1)}^{n} \\
& =\left\|x_{n}-p\right\|+\varphi_{n},
\end{aligned}
$$

where $\varphi_{n}=Q_{3} \mu_{n}\left\|x_{n}-p\right\|+Q_{3}\left(\mu_{n}+l_{n}\right)+\Gamma_{(1)}^{n}$. Since $\left\{x_{n}-p\right\}$ is bounded and $\sum_{n=1}^{\infty} \mu_{n}<\infty, \sum_{n=1}^{\infty} l_{n}<\infty$ and $\sum_{n=1}^{\infty} \Gamma_{(1)}^{n}<\infty$, we have $\sum_{n=1}^{\infty} \varphi_{n}<\infty$. Thus, 3.11 implies

$$
\inf _{p \in \mathcal{F}}\left\|x_{n+1}-p\right\| \leq \inf _{p \in \mathcal{F}}\left\|x_{n}-p\right\|+\varphi_{n}
$$

that is

$$
d\left(x_{n+1}, \mathcal{F}\right) \leq d\left(x_{n}, \mathcal{F}\right)+\varphi_{n},
$$

by Lemma 2.1 (i), It follows from (3.12) that we have $\lim _{n \rightarrow \infty} d\left(x_{n}, \mathcal{F}\right)$ exist. But $\liminf _{n \rightarrow \infty} d\left(x_{n}, \mathcal{F}\right)=0$. It follows from (3.12) and Lemma 2.1 (ii) that we get $\lim _{n \rightarrow \infty} d\left(x_{n}, \mathcal{F}\right)=0$.

Now, given $\epsilon>0$, since $\lim _{n \rightarrow \infty} d\left(x_{n}, \mathcal{F}\right)=0$ and $\sum_{n=1}^{\infty} \varphi_{n}<\infty$, there exists an integer $N_{1}>0$ such that for all $n \geq N_{1}, d\left(x_{n}, \mathcal{F}\right) \leq \frac{\epsilon}{4}$ and $\sum_{j=n}^{\infty} \varphi_{j} \leq \frac{\epsilon}{4}$. So, we get $d\left(x_{N_{1}}, \mathcal{F}\right) \leq \frac{\epsilon}{4}$ and $\sum_{j=N_{1}}^{\infty} \varphi_{j} \leq \frac{\epsilon}{4}$. This means that there exists a $q_{1} \in \mathcal{F}$ such that $\left\|x_{N_{1}}-q_{1}\right\| \leq \frac{\epsilon}{4}$. So for all integers $n \geq N_{1}, m \geq 1$, we obtain from (3.11) that

$$
\begin{aligned}
\left\|x_{n+m}-x_{n}\right\| & \leq\left\|x_{n+m}-q_{1}\right\|+\left\|x_{n}-q_{1}\right\| \\
& \leq\left\|x_{N_{1}}-q_{1}\right\|+\sum_{j=N_{1}}^{n+m-1} \varphi_{j}+\left\|x_{N_{1}}-q_{1}\right\|+\sum_{j=N_{1}}^{n-1} \varphi_{j} \\
& \leq\left\|x_{N_{1}}-q_{1}\right\|+\sum_{j=N_{1}}^{\infty} \varphi_{j}+\left\|x_{N_{1}}-q_{1}\right\|+\sum_{j=N_{1}}^{\infty} \varphi_{j} \\
& \leq \frac{\epsilon}{4}+\frac{\epsilon}{4}+\frac{\epsilon}{4}+\frac{\epsilon}{4} \\
& =\epsilon
\end{aligned}
$$


Hence, $\left\{x_{n}\right\}$ is a Cauchy sequences in $E$; and since $E$ is complete there exists $x^{*} \in E$ such that $x_{n} \rightarrow x^{*}$ as $n \rightarrow \infty$.We will prove that $x^{*}$ is a common fixed point of $T_{i}(i=1,2)$, that is, we will show that $x^{*} \in \mathcal{F}$. Suppose for contradiction that $x^{*} \in \mathcal{F}^{c}$ (where $\mathcal{F}^{c}$ denotes the complement of $\mathcal{F}$ ). Since $\mathcal{F}$ is a closed subset of $E$ (recall each $T_{i}, i=1,2$ is continuous), we have that $d\left(x^{*}, \mathcal{F}\right)>0$. For all $q_{1} \in \mathcal{F}$, we have $\left\|x^{*}-q_{1}\right\| \leq\left\|x^{*}-x_{n}\right\|+\left\|x_{n}-q_{1}\right\|$ which implies

$$
d\left(x^{*}, \mathcal{F}\right) \leq\left\|x_{n}-x^{*}\right\|+d\left(x_{n}, \mathcal{F}\right),
$$

so that as $n \rightarrow \infty$ we have $d\left(x^{*}, \mathcal{F}\right)=0$ which contradicts $d\left(x^{*}, \mathcal{F}\right)>0$. Thus, $x^{*}$ is a common fixed point of $T_{i}, i=1,2$. This completes the proof.

Letting $\beta_{n}^{\prime}=\gamma_{n}^{\prime} \equiv 0$ and $\alpha_{n}^{\prime} \equiv 1$ in Theorem 3.3 , we obtain the following modified Mann iterative scheme with errors convergence.

Theorem 3.4. Let $E$ be a real Banach space, let $K$ be a nonempty closed convex subset of $E$ which is also a nonexpansive retract of $E$, and $T_{1}, T_{2}: K \rightarrow E$ be two continuous total asymptotically nonexpansive nonself-mappings with sequences $\left\{\mu_{n}\right\},\left\{l_{n}\right\}$ defined by 1.9 such that $\sum_{n=1}^{\infty} \mu_{n}<\infty, \sum_{n=1}^{\infty} l_{n}<\infty$ and $\mathcal{F}:=$ $F\left(T_{1}\right) \cap F\left(T_{2}\right)=\left\{x \in K: T_{1} x=T_{2} x=x\right\} \neq \varnothing$. Assume that there exist $M, M^{*}>0$ such that $\phi(\lambda) \leq M^{*} \lambda$ for all $\lambda \geq M$. Suppose that $\left\{u_{n}\right\},\left\{v_{n}\right\}$ are bounded sequences in $K$ such that $\sum_{n=1}^{\infty} \gamma_{n}<\infty, \sum_{n=1}^{\infty} \gamma_{n}^{\prime}<\infty$. Starting from an arbitrary $x_{1} \in K$, define the sequence $\left\{x_{n}\right\}$ by recursion (1.11). Then, the sequence $\left\{x_{n}\right\}$ converges strongly to a common fixed point of $\left\{T_{i}\right\}_{i=1}^{2}$ if and only if $\lim _{n \rightarrow \infty} d\left(x_{n}, \mathcal{F}\right)=0$, where $d\left(x_{n}, \mathcal{F}\right)=\inf _{p \in \mathcal{F}}\left\|x_{n}-p\right\|, n \geq 1$.

Theorem 3.5. Let $E$ be a real Banach space, let $K$ be a nonempty closed convex subset of $E$ which is also a nonexpansive retract of $E$, and $T_{1}, T_{2}: K \rightarrow E$ be two continuous total asymptotically nonexpansive nonself-mappings with sequences $\left\{\mu_{n}\right\},\left\{l_{n}\right\}$ defined by 1.9 such that $\sum_{n=1}^{\infty} \mu_{n}<\infty, \sum_{n=1}^{\infty} l_{n}<\infty$ and $\mathcal{F}:=$ $F\left(T_{1}\right) \cap F\left(T_{2}\right)=\left\{x \in K: T_{1} x=T_{2} x=x\right\} \neq \varnothing$. Assume that there exist $M, M^{*}>0$ such that $\phi(\lambda) \leq M^{*} \lambda$ for all $\lambda \geq M$; and that one of $T_{i}, i=1,2$ is demicompact (without loss of generality, we assume that $T_{1}$ is demicompact). Suppose that $\left\{u_{n}\right\},\left\{v_{n}\right\}$ are bounded sequences in $K$ such that $\sum_{n=1}^{\infty} \gamma_{n}<\infty, \sum_{n=1}^{\infty} \gamma_{n}^{\prime}<\infty$. For an arbitrary $x_{1} \in K$, define the sequence $\left\{x_{n}\right\}$ by recursion (1.10).

Suppose that

(i) $0<\liminf _{n \rightarrow \infty} \alpha_{n}$ and $0<\liminf _{n \rightarrow \infty} \gamma_{n}<\limsup _{n \rightarrow \infty} \gamma_{n}<1$,

(ii) $0<\liminf _{n \rightarrow \infty} \alpha_{n}^{\prime}$ and $0<\liminf _{n \rightarrow \infty} \gamma_{n}^{\prime}<\lim _{\sup _{n \rightarrow \infty}} \gamma_{n}^{\prime}<1$.

Then the sequence $\left\{x_{n}\right\}$ converges strongly to some common fixed points of $\left\{T_{i}\right\}_{i=1}^{2}$.

Proof. $\left\{u_{n}\right\},\left\{v_{n}\right\}$ are bounded, it follows from Lemma 3.1 that $\left\{u_{n}-x_{n}\right\}$ and $\left\{v_{n}-x_{n}\right\}$ are all bounded. We set

$$
\begin{aligned}
r_{1} & =\sup \left\{\left\|u_{n}-x_{n}\right\|: n \geq 1\right\}, \quad r_{2}=\sup \left\{\left\|v_{n}-x_{n}\right\|: n \geq 1\right\}, \\
r & =\max \left\{r_{i}: i=1,2\right\} .
\end{aligned}
$$

It follows from (1.10) and Lemma 3.2 that

$$
\begin{aligned}
\left\|y_{n}-x_{n}\right\| & =\left\|P\left(\alpha_{n}^{\prime} x_{n}+\beta_{n}^{\prime} T_{1}\left(P T_{1}\right)^{n-1} x_{n}+\gamma_{n}^{\prime} v_{n}\right)-x_{n}\right\| \\
& \leq \beta_{n}^{\prime}\left\|T_{1}\left(P T_{1}\right)^{n-1} x_{n}-x_{n}\right\|+\gamma_{n}^{\prime}\left\|v_{n}-x_{n}\right\| \\
& \leq\left\|T_{1}\left(P T_{1}\right)^{n-1} x_{n}-x_{n}\right\|+\gamma_{n}^{\prime} r
\end{aligned}
$$

This together with (3.10) implies that

$$
\lim _{n \rightarrow \infty}\left\|y_{n}-x_{n}\right\|=0
$$


We find the following from (1.10) and (3.14),

$$
\begin{aligned}
\left\|x_{n+1}-x_{n}\right\| & =\left\|P\left(\alpha_{n} y_{n}+\beta_{n} T_{2}\left(P T_{2}\right)^{n-1} y_{n}+\gamma_{n} u_{n}\right)-P x_{n}\right\| \\
& \leq \alpha_{n}\left\|y_{n}-x_{n}\right\|+\beta_{n}\left\|T_{2}\left(P T_{2}\right)^{n-1} y_{n}-x_{n}\right\|+\gamma_{n}\left\|u_{n}-x_{n}\right\| \\
& \leq \alpha_{n}\left\|y_{n}-x_{n}\right\|+\beta_{n}\left[\left\|y_{n}-x_{n}\right\|+\mu_{n} \phi\left(\left\|y_{n}-x_{n}\right\|\right)+l_{n}\right]+\gamma_{n} r \\
& \leq\left(1+Q \mu_{n}\right)\left\|y_{n}-x_{n}\right\|+Q\left(\mu_{n}+l_{n}\right)+\gamma_{n} r \\
& \rightarrow 0, \text { as } n \rightarrow \infty
\end{aligned}
$$

for some constant $Q>0$. It follows from Lemma 3.2 and (3.15) that

$$
\begin{aligned}
\left\|x_{n}-T_{i}\left(P T_{i}\right)^{n-2} x_{n}\right\| \leq & \left\|x_{n}-x_{n-1}\right\|+\left\|x_{n-1}-T_{i}\left(P T_{i}\right)^{n-2} x_{n-1}\right\| \\
& +\left\|T_{i}\left(P T_{i}\right)^{n-2} x_{n-1}-T_{i}\left(P T_{i}\right)^{n-2} x_{n}\right\| \\
\leq & 2\left\|x_{n}-x_{n-1}\right\|+\left\|x_{n-1}-T_{i}\left(P T_{i}\right)^{n-2} x_{n-1}\right\| \\
& +\mu_{n-1} \phi\left(\left\|x_{n}-x_{n-1}\right\|\right)+l_{n-1} \\
\rightarrow & 0, \text { as } n \rightarrow \infty, \quad \text { for } i=1,2 .
\end{aligned}
$$

Since $T_{i}$ is continuous and $P$ is nonexpansive retraction, it follows from 3.16 that for $i=1,2$

$$
\left\|T_{i}\left(P T_{i}\right)^{n-1} x_{n}-T_{i} x_{n}\right\|=\left\|T_{i} P\left(T_{i}\left(P T_{i}\right)^{n-2}\right) x_{n}-T_{i} P x_{n}\right\| \rightarrow 0, \text { as } n \rightarrow \infty .
$$

Hence, by Lemma 3.2 and (3.17), we have

$$
\begin{aligned}
\left\|x_{n}-T_{i} x_{n}\right\| & \leq\left\|x_{n}-T_{i}\left(P T_{i}\right)^{n-1} x_{n}\right\|+\left\|T_{i}\left(P T_{i}\right)^{n-1} x_{n}-T_{i} x_{n}\right\| \\
& \rightarrow 0, \text { as } n \rightarrow \infty, \quad \text { for } i=1,2 .
\end{aligned}
$$

Since $T_{1}$ is demicompact, from the fact that $\lim _{n \rightarrow \infty}\left\|x_{n}-T_{1} x_{n}\right\|=0$ and $\left\{x_{n}\right\}$ is bounded, there exists a subsequence $\left\{x_{n_{k}}\right\}$ of $\left\{x_{n}\right\}$ that converges strongly to some $q \in K$ as $k \rightarrow \infty$. Thus, it follows from (3.18) that $T_{1} x_{n_{k}} \rightarrow q, T_{2} x_{n_{k}} \rightarrow q$ as $k \rightarrow \infty$, and it follows from (3.17) and $T_{i}$ is continuous that

$$
\begin{aligned}
\left\|T_{i}\left(P T_{i}\right)^{n_{k}-1} x_{n_{k}}-T_{i} q\right\| \leq & \left\|T_{i}\left(P T_{i}\right)^{n_{k}-1} x_{n_{k}}-T_{i} x_{n_{k}}\right\|+\left\|T_{i} x_{n_{k}}-T_{i} q\right\| \\
\leq & \left\|T_{i} P\left(T_{i}\left(P T_{i}\right)^{n_{k}-2}\right) x_{n_{k}}-T_{i} P x_{n_{k}}\right\| \\
& +\left\|T_{i} x_{n_{k}}-T_{i} q\right\| \\
\rightarrow & 0, \text { as } n \rightarrow \infty, \quad \text { for } i=1,2 .
\end{aligned}
$$

Observe that

$$
\left\|q-T_{1} q\right\| \leq\left\|q-x_{n_{k}}\right\|+\left\|x_{n_{k}}-T_{1}\left(P T_{1}\right)^{n_{k}-1} x_{n_{k}}\right\|+\left\|T_{1}\left(P T_{1}\right)^{n_{k}-1} x_{n_{k}}-T_{1} q\right\| .
$$

Taking limit as $k \rightarrow \infty$ and using the fact that Lemma 3.2 and (3.19) we get that $T_{1} q=q$ and so $q \in F\left(T_{1}\right)$. Also, we have

$$
\left\|q-T_{2} q\right\| \leq\left\|q-x_{n_{k}}\right\|+\left\|x_{n_{k}}-T_{2}\left(P T_{2}\right)^{n_{k}-1} x_{n_{k}}\right\|+\left\|T_{2}\left(P T_{2}\right)^{n_{k}-1} x_{n_{k}}-T_{2} q\right\| .
$$

Taking limit as $k \rightarrow \infty$ and using the fact that Lemma 3.2 and 3.19 we get that $T_{2} q=q$ and so $q \in F\left(T_{2}\right)$. Thus, we obtain that $q \in \mathcal{F}$. It follows from (3.6), Lemma 2.1 and $\lim _{k \rightarrow \infty} x_{n_{k}}=q$ that $\left\{x_{n}\right\}$ converges strongly to $q \in \mathcal{F}$. This completes the proof.

The following result gives a strong convergence theorem for two total asymptotically nonexpansive nonself-mappings in a real Banach space satisfying condition $\left(A^{\prime}\right)$. 
Theorem 3.6. Let $E$ be a real uniformly convex Banach space, let $K$ be a nonempty closed convex subset of $E$ which is also a nonexpansive retract of $E$, and $T_{1}, T_{2}: K \rightarrow E$ be two total asymptotically nonexpansive nonself-mappings with sequences $\left\{\mu_{n}\right\},\left\{l_{n}\right\}$ defined by 1.9 such that $\sum_{n=1}^{\infty} \mu_{n}<\infty, \sum_{n=1}^{\infty} l_{n}<\infty$ and $\mathcal{F}:=$ $F\left(T_{1}\right) \cap F\left(T_{2}\right)=\left\{x \in K: T_{1} x=T_{2} x=x\right\} \neq \varnothing$. Assume that there exist $M, M^{*}>0$ such that $\phi(\lambda) \leq M^{*} \lambda$ for all $\lambda \geq M$. Suppose that $\left\{u_{n}\right\},\left\{v_{n}\right\}$ are bounded sequences in $K$ such that $\sum_{n=1}^{\infty} \gamma_{n}<\infty, \sum_{n=1}^{\infty} \gamma_{n}^{\prime}<\infty$. For an arbitrary $x_{1} \in K$, define the sequence $\left\{x_{n}\right\}$ by recursion (1.10).

Suppose that $T_{1}$ and $T_{2}$ satisfy condition $\left(A^{\prime}\right)$ and

(i) $0<\liminf _{n \rightarrow \infty} \alpha_{n}$ and $0<\liminf _{n \rightarrow \infty} \gamma_{n}<\limsup _{n \rightarrow \infty} \gamma_{n}<1$,

(ii) $0<\liminf _{n \rightarrow \infty} \alpha_{n}^{\prime}$ and $0<\liminf _{n \rightarrow \infty} \gamma_{n}^{\prime}<\lim _{\sup _{n \rightarrow \infty}} \gamma_{n}^{\prime}<1$.

Then the sequence $\left\{x_{n}\right\}$ converges strongly to some common fixed points of $\left\{T_{i}\right\}_{i=1}^{2}$.

Proof. By Lemma 3.1, we see that $\lim _{n \rightarrow \infty}\left\|x_{n}-p\right\|$ and so, $\lim _{n \rightarrow \infty} d\left(x_{n}, \mathcal{F}\right)$ exists for all $p \in \mathcal{F}$. Also, from (3.18), $\lim _{n \rightarrow \infty}\left\|x_{n}-T_{i} x_{n}\right\|=0(i=1,2)$. It follows from condition $\left(A^{\prime}\right)$ that

$$
\lim _{n \rightarrow \infty} f\left(d\left(x_{n}, \mathcal{F}\right)\right) \leq \lim _{n \rightarrow \infty}\left(\frac{1}{2}\left(\left\|x_{n}-T_{1} x_{n}\right\|+\left\|x_{n}-T_{2} x_{n}\right\|\right)\right)=0 .
$$

That is,

$$
\lim _{n \rightarrow \infty} f\left(d\left(x_{n}, \mathcal{F}\right)\right)=0 .
$$

Since $f:[0, \infty) \rightarrow[0, \infty)$ is a nondecreasing function satisfying $f(0)=0, f(t)>0$ for all $t \in(0, \infty)$, hence, we have

$$
\lim _{n \rightarrow \infty} d\left(x_{n}, \mathcal{F}\right)=0 .
$$

Now we can take a subsequence $\left\{x_{n j}\right\}$ of $\left\{x_{n}\right\}$ and sequence $\left\{y_{j}\right\} \subset \mathcal{F}$ such that $\left\|x_{n j}-y_{j}\right\|<2^{-j}$ for all integers $j \geq 1$. Using the proof method of Tan and Xu [21], we have

$$
\left\|x_{n_{j+1}}-y_{j}\right\| \leq\left\|x_{n j}-y_{j}\right\|<2^{-j}
$$

and therefore

$$
\begin{aligned}
\left\|y_{j+1}-y_{j}\right\| & \leq\left\|y_{j+1}-x_{n_{j+1}}\right\|+\left\|x_{n_{j+1}}-y_{j}\right\| \\
& \leq 2^{-(j+1)}+2^{-j} \\
& <2^{-j+1}
\end{aligned}
$$

We get that $\left\{y_{j}\right\}$ is a Cauchy sequence in $\mathcal{F}$ and so it converges. Let $y_{j} \rightarrow y$. Since $\mathcal{F}$ is closed, hence, $y \in \mathcal{F}$ and then $x_{n j} \rightarrow y$. As $\lim _{n \rightarrow \infty}\left\|x_{n}-p\right\|$ exists, $x_{n} \rightarrow y \in \mathcal{F}$. The proof is completed.

Letting $\beta_{n}^{\prime}=\gamma_{n}^{\prime} \equiv 0$ and $\alpha_{n}^{\prime} \equiv 1$ in Theorem 3.6, we obtain the following modified Mann iterative scheme with errors convergence.

Theorem 3.7. Let $E$ be a real uniformly convex Banach space, let $K$ be a nonempty closed convex subset of $E$ which is also a nonexpansive retract of $E$, and $T_{1}, T_{2}: K \rightarrow E$ be two total asymptotically nonexpansive nonself-mappings with sequences $\left\{\mu_{n}\right\},\left\{l_{n}\right\}$ defined by 1.9p such that $\sum_{n=1}^{\infty} \mu_{n}<\infty, \sum_{n=1}^{\infty} l_{n}<\infty$ and $\mathcal{F}:=$ $F\left(T_{1}\right) \cap F\left(T_{2}\right)=\left\{x \in K: T_{1} x=T_{2} x=x\right\} \neq \varnothing$. Assume that there exist $M, M^{*}>0$ such that $\phi(\lambda) \leq M^{*} \lambda$ for all $\lambda \geq M$. Suppose that $\left\{u_{n}\right\},\left\{v_{n}\right\}$ are bounded sequences in $K$ such that $\sum_{n=1}^{\infty} \gamma_{n}<\infty, \sum_{n=1}^{\infty} \gamma_{n}^{\prime}<\infty$. For an arbitrary $x_{1} \in K$, define the sequence $\left\{x_{n}\right\}$ by recursion (1.11).

Suppose that $T_{1}$ and $T_{2}$ satisfy condition $\left(A^{\prime}\right)$ and

(i) $0<\liminf _{n \rightarrow \infty} \alpha_{n}$ and $0<\liminf _{n \rightarrow \infty} \gamma_{n}<\limsup _{n \rightarrow \infty} \gamma_{n}<1$,

(ii) $0<\liminf _{n \rightarrow \infty} \alpha_{n}^{\prime}$ and $0<\liminf _{n \rightarrow \infty} \gamma_{n}^{\prime}<\lim _{\sup _{n \rightarrow \infty}} \gamma_{n}^{\prime}<1$.

Then the sequence $\left\{x_{n}\right\}$ converges strongly to some common fixed points of $\left\{T_{i}\right\}_{i=1}^{2}$. 
Remark 3.8. Since total asymptotically nonexpansive mappings reduces to asymptotically nonexpansive in the intermediate sense mappings, Theorem 3.6 and 3.7 extend and improve Theorem 3.7 and 3.8 of Nilsrakoo [15.

Remark 3.9. If $T_{1}$ and $T_{2}$ are asymptotically nonexpansive mappings, then $l_{n}=0$ and $\phi(\lambda)=\lambda$ so that the assumption that there exist $M, M^{*}>0$ such that $\phi(\lambda) \leq M^{*} \lambda$ for all $\lambda \geq M, i \in\{1,2\}$ in the above theorems is no longer needed. Hence, the results in the above theorems also hold for asymptotically nonexpansive mappings. Therefore, the results in this paper improve and extend the corresponding results of [5], 7], [12], [15], [16] and [18 from asymptotically nonexpansive mappings (or asymptotically nonexpansive in the intermediate sense) mappings to nonself total asymptotically nonexpansive mappings under general conditions. Moreover, the iterative sequence (1.11) is replaced by the modified Ishikawa iterative scheme (1.10).

Example 3.10. Let $E$ is the real line with the usual norm $||,. K=[0, \infty)$ and $P$ be the identity mapping. Assume that $T_{1} x=x$ and $T_{2} x=\sin x$ for $x \in K$. Let $\phi$ be a strictly increasing continuous function such that $\phi: \mathbb{R}^{+} \rightarrow \mathbb{R}^{+}$with $\phi(0)=0$. Let $\left\{\mu_{n}\right\}_{n \geq 1}$ and $\left\{l_{n}\right\}_{n \geq 1}$ be two nonnegative real sequences defined by $\mu_{n}=\frac{1}{n^{2}}$ and $l_{n}=\frac{1}{n^{3}}$, for all $n \geq 1\left(\lim _{n \rightarrow \infty} \mu_{n}=0\right.$ and $\left.\lim _{n \rightarrow \infty} l_{n}=0\right)$. Since $T_{1} x=x$ for $x \in K$, we have

$$
\left|T_{1}^{n} x-T_{1}^{n} y\right| \leq|x-y| .
$$

For all $x, y \in K$, we obtain

$$
\begin{aligned}
& \left|T_{1}^{n} x-T_{1}^{n} y\right|-|x-y|-\mu_{n} \phi(|x-y|)-l_{n} \\
\leq & |x-y|-|x-y|-\mu_{n} \phi(|x-y|)-l_{n} \\
\leq & 0
\end{aligned}
$$

for all $n=1,2, \ldots,\left\{\mu_{n}\right\}_{n \geq 1}$ and $\left\{l_{n}\right\}_{n \geq 1}$ with $\mu_{n}, l_{n} \rightarrow 0$ as $n \rightarrow \infty$ and so $T_{1}$ is a total asymptotically nonexpansive mapping. Also, $T_{2} x=\sin x$ for $x \in K$, we have

$$
\left|T_{1}^{n} x-T_{1}^{n} y\right| \leq|x-y| .
$$

For all $x, y \in K$, we obtain

$$
\begin{aligned}
& \left|T_{2}^{n} x-T_{2}^{n} y\right|-|x-y|-\mu_{n} \phi(|x-y|)-l_{n} \\
\leq & |x-y|-|x-y|-\mu_{n} \phi(|x-y|)-l_{n} \\
\leq & 0
\end{aligned}
$$

for all $n=1,2, \ldots,\left\{\mu_{n}\right\}_{n \geq 1}$ and $\left\{l_{n}\right\}_{n \geq 1}$ with $\mu_{n}, l_{n} \rightarrow 0$ as $n \rightarrow \infty$ and so $T_{2}$ is a total asymptotically nonexpansive mapping. Clearly, $\mathcal{F}:=F\left(T_{1}\right) \cap F\left(T_{2}\right)=\{0\}$. Set

$$
\alpha_{n}^{\prime}=\alpha_{n}=\frac{n}{n+1}, \beta_{n}^{\prime}=\beta_{n}=\frac{1}{n^{2}}, \gamma_{n}^{\prime}=\gamma_{n}=\frac{n^{2}-n-1}{n^{3}+n^{2}} \text { and } v_{n}=u_{n}=\frac{1}{n+1}
$$

for $n \geq 1$. Thus, the conditions of Theorem 3.3 are fulfilled. Therefore, we can invoke Theorem 3.3 to demonstrate that the iterative sequence $\left\{x_{n}\right\}$ defined by 1.10 ) converges strongly to 0 . 
The following table has been obtained by FORTRAN 90 Programming Language.

\begin{tabular}{|c|c|c|}
\hline$\left\{x_{n}\right\}$ & Iteration $[1.10)$ & Iteration $\mathbf{1 . 1 0}$ \\
\hline$x_{1}$ & 1.000000 & 3.000000 \\
\hline$x_{2}$ & $1.034148 E-01$ & -1.183136 \\
\hline$x_{3}$ & $1.703063 E-01$ & $-2.192974 E-01$ \\
\hline$x_{4}$ & $1.297774 E-01$ & $-5.604304 E-02$ \\
\hline$x_{5}$ & $8.572214 E-02$ & $-4.820751 E-03$ \\
\hline$x_{6}$ & $5.691798 E-02$ & $9.707832 E-03$ \\
\hline$x_{7}$ & $3.521213 E-02$ & $1.211889 E-02$ \\
\hline$x_{8}$ & $2.292063 E-02$ & $1.102576 E-02$ \\
\hline$x_{9}$ & $1.420441 E-02$ & $8.534811 E-03$ \\
\hline$x_{10}$ & $9.505245 E-03$ & $6.647571 E-03$ \\
\hline$\vdots$ & $\vdots$ & $\vdots$ \\
\hline$x_{50}$ & $2.756935 E-05$ & $2.756935 E-05$ \\
\hline$\vdots$ & $\vdots$ & $\vdots$ \\
\hline$x_{100}$ & $3.345823 E-06$ & $3.345823 E-06$ \\
\hline$\vdots$ & $\vdots$ & $\vdots$ \\
\hline
\end{tabular}

\section{Acknowledgements:}

The authors would like to thank Prof. Murat OZDEMIR and the referees for their helpful comments.

\section{References}

[1] Ya. I. Albert, C. E. Chidume, H. Zegeye, Approximating fixed points of total asymptotically nonexpansive mappings, Fixed Point Theory Appl., 2006 (2006) article ID 10673. 1

[2] V. Berinde, Iterative approximation of fixed points. Second edition, Lecture Notes in Mathematics, 1912, Springer, Berlin, 2007. 1

[3] R. E. Bruck, T. Kuczumow, S. Reich, Convergence of iterates of asymptotically nonexpansive mappings in Banach spaces with the uniform Opial property, in: Colloq. Math., vol. LXV Fasc. 2 (1993) pp. 169-179. 1, 1

[4] C. E. Chidume: Geometric Properties of Banach Spaces and Nonlinear Iterations, Springer, Berlin, 2009. 1

[5] C. E. Chidume, E. U. Ofoedu, H. Zegeye, Strong and weak convergence theorems for fixed points of asymptotically nonexpansive mappings, J. Math. Anal. Appl., 280 (2003) 364-374. 1 , 3.9

[6] C. E. Chidume, E. U. Ofoedu, Approximation of common fixed points for finite families of total asymptotically nonexpansive mappings, J. Math. Anal. Appl., 333 (2007) 128-141. 1

[7] Y. J. Cho, H. Y. Zhou, G. Guo, Weak and strong convergence theorems for three-step Iterations with errors for asymptotically nonexpansive mappings, Comput. Math. Appl., 47 (2004) 707-717. 2.2 3.9

[8] K. Goebel, W. A. Kirk, A fixed point theorem for asymptotically nonexpansive mappings, Proc. Amer. Math. Soc., 35 (1972) 171-174. 1, 1

[9] G. Hu, L. Yang, Strong convergence of the modified three step iterative process in Banach spaces, Dyn. Contin. Discrete Impuls. Syst. Ser. A Math. Anal., 15 (2008) 555-571. 1.4

[10] S. H. Khan, W. Takahashi, Approximanting common fixed points of two asymptotically nonexpansive mappings, Sci. Math. Jpn., 53 (1) (2001) 143-148. 1

[11] S. H. Khan, N. Hussain, Convergence theorems for nonself asymptotically nonexpansive mappings, Comput. Math. Appl., 55 (2008) 2544-2553. 1

[12] G. E. Kim, T. H. Kim, Mann and Ishikawa iterations with errors for non-Lipschitzian mappings in Banach spaces, Comput. Math. Appl., 42 (2001) 1565-1570. 1, 3.9

[13] W. A. Kirk, Fixed point theorems for non-Lipschitzian mappings of asymptotically nonexpansive type, Israel J. Math. 17 (1974) 339-346. 1

[14] N. Maiti, M. K. Ghosh, Approximating fixed points by Ishikawa iterates, Bull. Aust. Math. Soc., 40 (1989) 113-117.2, 2

[15] W. Nilsrakoo, S. Saejung, A new strong convergence Theorem for non-Lipschitzian Mappings in a uniformly convex Banach Space, Rostock, Math. Kolloq., 64 (2009) 75-86. 1, 1, 3.8, 3.9 
[16] M. O. Osilike, S. C. Aniagbosar, Weak and strong convergence theorems for fixed points of asymptotically nonexpansive mappings, Math. Comput. Modelling, 32 (2000) 1181-1191. 1. 3.9

[17] X. Qin, Y. Su, M. Shang, Approximating common fixed points of non-self asymptotically nonexpansive mappings in Banach Spaces, J. Appl. Math. Comput., 26 (2008) 233-246. 1

[18] J. Schu, Iterative construction of fixed points of asymptotically nonexpansive mappings, J. Math. Anal. Appl., 158 (1991) 407-413. 1, 3.9

[19] J. Schu, Weak and strong convergence of a fixed points of asymptotically nonexpansive mappings, Bull. Aust. Math. Soc., 43 (1991) 153-159. 1

[20] H. F. Senter, W. G. Dotson, Approximating fixed points of nonexpansive mappings, Proc. Amer. Math. Soc., 44 (1974) 375-380. 2, 2

[21] K. K. Tan, H. K. Xu, Approximating fixed points of nonexpansive mappings by the Ishikawa iteration process, J. Math. Anal. Appl., 178 (1993) 301-308. 1, 2, 2.1, 3

[22] Y. Xu, Ishikawa and Mann iterative processes with errors for nonlinear strongly accretive operator equations, J. Math. Anal. Appl., 224 (1998) 91-101. 1 